\title{
Colonoscopic post-polypectomy bleeding in patients on uninterruptedclopidogrel therapy: A systematic review and meta-analysis
}

\author{
DE-FENG LI ${ }^{1 *}$, XIN CHANG $^{2 *}$, XUE FANG $^{2}$, JIAN-YAO WANG $^{3}$, ZHI-CHAO YU $^{1}$, CHENG WEI $^{1}$, \\ FENG XIONG ${ }^{1}$, ZHENG-LEI XU ${ }^{1}$, DING-GUO ZHANG ${ }^{1}$, TING-TING LIU ${ }^{1}$, \\ MING-HAN LUO ${ }^{1}$, LI-SHENG WANG ${ }^{1}$ and JUN YAO ${ }^{1}$
}

\author{
${ }^{1}$ Department of Gastroenterology, The Second Clinical Medicine College (Shenzhen People's Hospital) of Jinan University, \\ Shenzhen, Guangdong 518020; ${ }^{2}$ Department of Gastroenterology, Changhai Hospital, Second Military Medical \\ University, Shanghai 200433; ${ }^{3}$ Department of General Surgery, Shenzhen Children's Hospital, \\ Shenzhen, Guangdong 518020, P.R. China
}

Received May 14, 2019; Accepted October 25, 2019

DOI: $10.3892 / \mathrm{etm} .2020 .8597$

\begin{abstract}
Current guidelines recommend temporary cessation of clopidogrel for 7-10 days for patients on clopidogrel undergoing colonoscopy with polypectomy. However, recent prospective randomized controlled trials have advocated for uninterrupted clopidogrel, due to similar post-polypectomy bleeding (PPB) rates with and without continued clopidogrel therapy. Thus, a meta-analysis was conducted to assess the risk of PPB rate in patients on continued clopidogrel therapy. Systemically identified publications were used to compare the rate of PPB in patients on continued clopidogrel therapy with those who had interrupted clopidogrel therapy. The primary outcome was the incidence of PPB. The secondary outcomes were immediate PPB, delayed PPB and serious cardio-thrombotic events. This study has been registered in PROSPERO (no. CRD42018118325). A total of five studies were identified, which included 655 patients in the continued clopidogrel group and 6620 patients in the control group. There was an increased risk of $\mathrm{PPB}$ with continued clopidogrel $[\mathrm{P}=0.0003$; risk ratio
\end{abstract}

Correspondence to: Dr Jun Yao or Dr Li-Sheng Wang, Department of Gastroenterology, The Second Clinical Medicine College (Shenzhen People's Hospital) of Jinan University, 1017 East Gate Road, Shenzhen, Guangdong 518020, P.R. China

E-mail: yj_1108@126.com

E-mail: wangls168@163.com

${ }^{*}$ Contributed equally

Abbreviations: RCT, randomized controlled trials; PPB, post-polypectomy bleeding; RR, risk ratio; CI, confidence interval; CHD, coronary heart disease; AHA, American Heart Association; DAPT, dual antiplatelet therapy; NOS, Newcastle-Ottawa Scale; CRC, colorectal cancer

Key words: PPB, clopidogrel therapy, review and meta-analysis
(RR), 1.96; 95\% confidence interval (CI), 1.36-2.83). The rate of immediate PPB was slightly higher in the continued clopidogrel group (5.77\% vs. $1.77 \%$, respectively), but was not statistically significant $(\mathrm{P}=0.06$; $\mathrm{RR}, 1.57$; 95\% CI, 0.98-2.51). The rate of delayed PPB was increased in the continued clopidogrel group ( $\mathrm{P}=0.0008$; $\mathrm{RR}, 3.10 ; 95 \% \mathrm{CI}, 1.60-5.98)$. However, no significant difference in serious cardio-thrombotic events was observed within 30 days $(\mathrm{P}=0.74$; $\mathrm{RR}, 0.78$; 95\%CI, 0.18-3.40). Although continued clopidogrel therapy decreased the incidence of serious cardio-thrombotic events, the risk of delayed PPB was increased. Therefore, endoscopists should make all preparations to prevent bleeding in the perioperative period for patients at high thrombotic risk and on continued clopidogrel therapy, if polypectomy cannot be reasonably postponed.

\section{Introduction}

Coronary heart disease (CHD) is a major public health problem (1). In 2016, the American Heart Association reported that there were 400,000 deaths due to CHD each year in the United States, and that the number of new cases has increased to 785,000 (2). Dual antiplatelet therapy (DAPT) is a cornerstone treatment for arterial coronary disease, and second line for the prevention of cardiovascular and cerebrovascular events. Therefore, endoscopists are encountering increasing numbers of patients on DAPT.

Post-polypectomy bleeding (PPB) is the most common complication of colonoscopy with polypectomy, ranging in prevalence from $0.6-6.1 \%$ (3). Antiplatelet agents such as the thienopyridines and aspirin have been used widely to decrease thrombotic events, particularly in patients who have had coronary stents, peripheral stents for vascular disease, myocardial infarctions and cerebrovascular events (4). For patients on antiplatelet therapy undergoing polypectomy, the management of perioperative therapy is a common clinical dilemma (5). The physician needs to weigh the increased risk of PPB against the thrombotic risk caused by discontinuation of the antiplatelet 
agents. Although the interruption of clopidogrel decreases $\mathrm{PPB}$, it has been associated with higher mortality rates, due to complications such as stent thrombosis, myocardial infarction and stroke (6). Nonetheless, there is no consensus on how the risk of PPB and of thrombotic events should be balanced, resulting in considerable variability in current clinical practice (7). A retrospective study discovered that the incidence of delayed PPB within 30 days following polypectomy was significantly higher inpatients on clopidogrel and concomitant aspirin/nonsteroidal anti-inflammatory drugs (6). However, another study showed that the delayed PPB rate inpatients on clopidogrel was $<1 \%$, which was within acceptable ranges reported for the general population not undergoing clopidogrel therapy. There was no significant difference in the PPB rates between patients receiving and not receiving clopidogrel (8). However, a prospective study demonstrated that the rate of immediate PPB (persistent bleeding observed at the time of polypectomy) and delayed PPB was significantly higher in patients on uninterrupted thienopyridines (9). Moreover, two meta-analyses both demonstrated that continued clopidogrel therapy increased the risk of delayed PPB and suggested deferring elective polypectomy until it was safe to terminate clopidogrel therapy $(10,11)$. Therefore, the current guidelines recommend temporary cessation of thienopyridine agents prior to high-risk endoscopic procedures, such as polypectomy, but uninterrupted thienopyridines for low-risk endoscopic procedures, such as biopsy $(12,13)$. However, a recent prospective observational study showed that the risk of early major cardiac adverse events was increased to 7.04 following the cessation of antiplatelet agents, and was highest in the first 7 days (14). In addition, a meta-analysis revealed a notably high risk of major cardiac adverse events following the interruption of antiplatelet therapy in patients with coronary stents [odds rate (OR), 89.78; $95 \%$ confidence interval (CI), 29.9-269.6] (15). Interestingly, the most recent prospective study reported that patients on continued clopidogrel had a slightly higher incidence rate of immediate and delayed PPB compared with those on discontinued clopidogrel; however, this difference was not statistically significant (16). This observation could be challenged with guidelines and by most gastroenterologists (17).

Overall, the management of medications in the periprocedural period lacks sufficient data and guidelines (18). Thus, a meta-analysis was performed to assess the risks of immediate and delayed PPB associated with the continued use of clopidogrel during colonoscopy and polypectomy, based on the available medical literature.

\section{Materials and methods}

Search strategy. A systemic search was conducted via the PubMed (https://www.ncbi.nlm.nih.gov/pubmed/), Web of Science (http://webofscience.com) and Cochrane library (https://www.cochranelibrary.com/) databases to identify available publications, in order to compare PPB rates in patients on continued or discontinued clopidogrel. The keywords used are listed: 'clopidogrel or thienopyridine' and 'colonoscopy or polypectomy'. A manual search for additional relevant publications was also conducted by screening the included studies. This study was performed in accordance with the Preferred
Reporting Items for Systematic Reviews and Meta-Analysis guidelines (19). This study was registered in PROSPERO (no. CRD42018118325).

Inclusion and exclusion criteria. The inclusion criteria were as follows: i) Randomized controlled trials (RCTs) and retrospective cohort or case-control studies reported in English; ii) patients on continued clopidogrel and non-clopidogrel undergoing colonoscopic polypectomy; iii) defining immediate PPB as bleeding at the time of polypectomy; iv) defining delayed PPB as bleeding occurring as late as 4 weeks or 30 days after the procedure [in the present study, delayed PPB was considered to be clinically significant delayed PPB, which included hemodynamic instability and a hemoglobin drop of at least $2 \mathrm{~g} / 1$, hospitalization, packed red cell transfusion, endoscopy intervention or surgery (20)]; v) patients receiving concomitant aspirin or other non-steroidal anti-inflammatory drugs (NSAIDs); and vi) patients who had had their clopidogrel discontinued for $>5$ days were included and placed in the non-clopidogrel group. The exclusion criteria were as follows: i) Patients receiving concomitant anticoagulant medication, such as warfarin and heparin; and ii) patients who were not taking clopidogrel on the day of the polypectomy, or in whom polypectomy was not performed.

Outcomes. The primary outcome was the incidence of colonoscopic PPB inpatients on continued clopidogrel and those who received interrupted antiplatelet therapy. The secondary outcomes were immediate PPB, delayed PPB and serious cardio-thrombotic events.

Quality assessment. Quality assessment was independently carried out by three reviewers, according totheNewcastle-Ottawa Scale (NOS) (21) for retrospective case-control studies and the Jadad Scale (22) for prospective controlled trials. Total scores of 0-3, 4-5 and 6-8 corresponded to low, moderate and high quality in the retrospective case-control studies, respectively. Good trials had a score of 3-5, whereas total scores of 0-2 corresponded to poor trials in RCTs.

Statistical analysis. All pooled data were analyzed with Review Manager 5.3 software (Cochrane Informatics and Knowledge Management Department, http://tech.cochrane. org/revman/download). Dichotomous variables were expressed as a risk ratio (RR) with a $95 \%$ CI. The $\chi^{2}$ test and $\mathrm{I}^{2}$ test were used to test heterogeneity, and a value of 25,50 or $75 \%$ suggested low, moderate and high heterogeneity, respectively. The random-effects model was used for high heterogeneity; otherwise, the fixed-effects model was used (23). A two-sided $\mathrm{P}<0.05$ was considered to indicate a statistically significant difference. A funnel plot for colonoscopic PPB, immediate PPB and delayed PPB was generated to assess the body of literature for publication bias.

\section{Results}

Search results. A total of 42 studies were identified by the present search strategy, of which 39 were complete articles and three were abstracts. A total of 10 studies, including two meta-analyses, five complete articles and three abstracts 


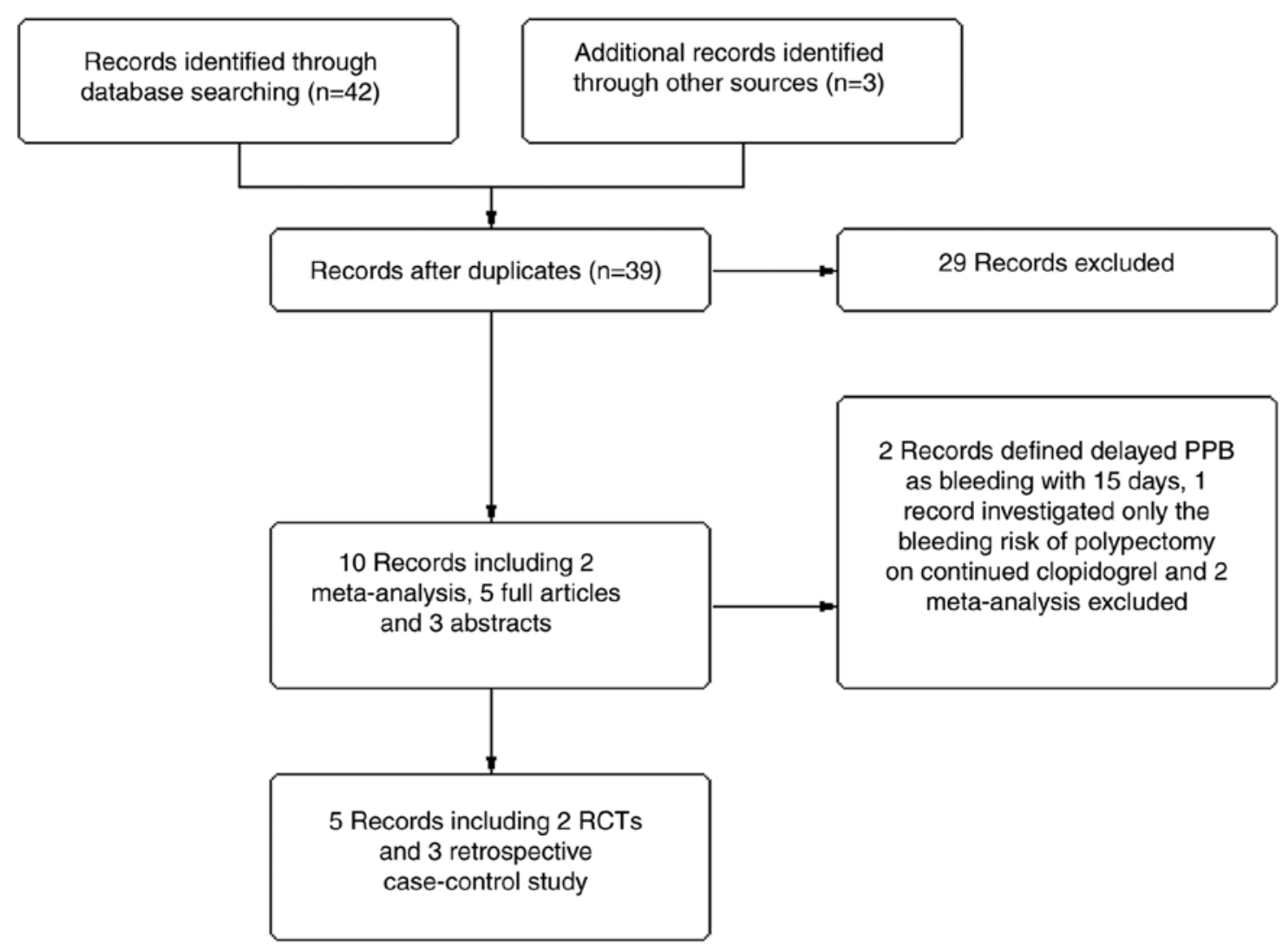

Figure 1. Flow diagram of literature search and selection. PPB, post-polypectomy bleeding; RCT, randomized controlled trials.

that assessed PPB rates in patients on continued clopidogrel met the inclusion criteria; however, two abstracts defined delayed PPB as bleeding within 15 days after polypectomy, one complete article investigated only the bleeding risk of polypectomy in patients on clopidogrel, and two meta-analysis articles were excluded. In total, four complete articles and one abstract, containing two prospective controlled trials, and three retrospective case-control studies were included in the present meta-analysis (Fig. 1).

Characteristics of included studies. Five eligible studies (Table I) reported on 7,275 patients undergoing colonoscopy with polypectomy, of whom 655 patients $(9.0 \%)$ were in the continued clopidogrel group and 6,620 patients (91\%) were in the control group. In the study by Singh et al (6), which included 142 patients on continued clopidogrel and 1,243 patients not on clopidogrel, $54 \%$ of patients on continued clopidogrel also received concomitant aspirin treatment, and $32 \%$ of patients in the control group were taking aspirin. The rate of immediate PPB was similar in both groups; however, the rate of delayed PPB was higher in the continued clopidogrel group. The study by Grossman et al (24) was published as a conference abstract, which included 70 patients taking clopidogrel only and 3,121 patients on non-clopidogrel therapy. Patients on continued clopidogrel demonstrated increased risk of both immediate and delayed PPB. In the study by Feagins et al (8), containing 118 patients on clopidogrel and 1,849 patients not taking clopidogrel, concomitant aspirin use was prevalent in $78.8 \%$ of clopidogrel users compared with $27.9 \%$ of the control group. It was found that continued clopidogrel did not increase the rate of delayed PPB. The Feagins et al (9) study was a prospective trial including 219 patients receiving clopidogrel and 297 patients not receiving clopidogrel; most of the patients were receiving concomitant aspirin. It was demonstrated that only delayed PPB was elevated in the continued clopidogrel group. The study by Chan et al (16) was also a prospective trial, including 226 patients treated with clopidogrel alone or in combination with other anti-platelet medications (e.g. aspirin). Of these patients, 106 received uninterrupted clopidogrel and 110 received a 7-day interruption of clopidogrel. It was demonstrated that continued clopidogrel resulted in a small increase in immediate and delayed PPB; however, this difference was not statistically significant.

Quality of included studies. Jadad scores and Newcastle-Ottawa scores for 2 RCTs and 3 retrospective case-control studies are shown in Tables II and III, respectively. All studies were scored as high quality.

Colonoscopic PPB. A total of five studies met the inclusion criteria and were eventually selected for analysis. The pooled PPB rate was calculated using a fixed-effect model, as the heterogeneity was not significantly different among these studies $(\mathrm{P}=0.47$; $\mathrm{I}^{2}, 0 \%$; Fig. 2). Based on the data of 655 patients on continued clopidogrel (49/655) and 6,620 patients in the control group (139/6,620), the RR of PPB increased to 1.96 in the continued clopidogrel group ( $\mathrm{P}=0.0003$; 95\%CI, 1.36-2.83; Fig. 2).

Immediate PPB. Four studies measured immediate PPB, where a total of $31 / 537$ patients on continued clopidogrel 
Table I. Characteristics of included studies.

\begin{tabular}{|c|c|c|c|c|c|c|c|}
\hline Author, year & $\begin{array}{l}\text { Study } \\
\text { type }\end{array}$ & $\begin{array}{c}\text { Patients with } \\
\text { polypectomy, n }\end{array}$ & $\begin{array}{c}\text { Clopidegrol } \\
\text { and ASA/ } \\
\text { NSAIDs } \\
\text { users, n }(\%)\end{array}$ & $\begin{array}{c}\text { Non-clopidegrol } \\
\text { and ASA/ } \\
\text { NSAIDs } \\
\text { users, n }(\%)\end{array}$ & $\begin{array}{l}\text { Clopidegrol } \\
\text { users with } \\
\text { bleed, n (\%) }\end{array}$ & $\begin{array}{c}\text { Non- } \\
\text { Clopidegrol } \\
\text { users with } \\
\text { bleed, n }(\%)\end{array}$ & (Refs.) \\
\hline Singh et al, 2010 & $\mathrm{RCC}$ & 3,601 & $\begin{array}{c}142(10.3 \%) \\
77(54.0 \%) \\
14(9.8 \%)\end{array}$ & $\begin{array}{c}1,243(89.7 \%) \\
398(32.0 \%) \\
170(13.7 \%)\end{array}$ & $\begin{array}{l}3 / 142(2.1 \%) \\
\text { Immediate; } \\
5 / 142(3.5 \%) \\
\text { Delayed }\end{array}$ & $\begin{array}{c}26 / 1,243(2.1 \%) \\
\text { Immediate; } \\
12 / 1,243(1.0 \%) \\
\text { Delayed }\end{array}$ & (6) \\
\hline Feagins et al, 2011 & $\mathrm{RCC}^{\mathrm{b}}$ & 6,031 & $\begin{array}{c}118(6.0 \%) ; \\
93(78.8 \%) ; \\
9(7.6 \%)\end{array}$ & $\begin{array}{l}1,849(94 \%) ; \\
515(27.9 \%), \\
271(14.7 \%)\end{array}$ & $\begin{array}{c}\text { N/A } \\
\text { Immediate; } \\
1 / 118(0.8 \%) \\
\text { Delayed }\end{array}$ & $\begin{array}{c}\text { N/A } \\
\text { Immediate; } \\
\text { 6/1,849 }(0.3 \%) \\
\text { Delayed }\end{array}$ & (8) \\
\hline Feagins et al, 2013 & $\mathrm{RCT}$ & 1,732 & $\begin{array}{c}219(42.4 \%) ; \\
192(87.7 \%) ; \\
25(11.5 \%)\end{array}$ & $\begin{array}{c}297(57.6 \%) ; \\
119(40.1 \%) ; \\
40(13.5 \%)\end{array}$ & $\begin{array}{l}16 / 219(7.3 \%) \\
\text { Immediate; } \\
5 / 210(2.4 \%) \\
\text { Delayed }\end{array}$ & $\begin{array}{c}\text { 14/297 }(4.7 \%) \\
\text { Immediate; } \\
\text { 0/286 } \\
\text { Delayed }\end{array}$ & (9) \\
\hline Chan et al, 2019 & $\mathrm{RCT}^{\mathrm{a}}$ & 449 & $\begin{array}{c}106(48.8 \%) ; \\
84(79.2 \%) ; \\
\text { N/A }\end{array}$ & $\begin{array}{c}111(52.2 \%) \\
86(78.2 \%) \\
\text { N/A }\end{array}$ & $\begin{array}{l}\text { 9/106 }(8.5 \%) \\
\text { Immediate; } \\
\text { 4/106 }(3.8 \%) \\
\text { Delayed }\end{array}$ & $\begin{array}{c}6 / 110(5.5 \%) \\
\text { Immediate; } \\
4 / 110(3.6 \%) \\
\text { Delayed }\end{array}$ & $(16)$ \\
\hline $\begin{array}{l}\text { Grossman et al, } \\
2010\end{array}$ & $\mathrm{RCC}$ & 3,191 & $\begin{array}{l}70(2.2 \%) \\
\text { N/A; N/A }\end{array}$ & $\begin{array}{c}3,121(97.8 \%) \\
627(20.1 \%) \\
90(2.9 \%)\end{array}$ & $\begin{array}{c}3 / 70(4.3 \%) \\
\text { Immediate; } \\
3 / 70(4.3 \%) \\
\text { Delayed }\end{array}$ & $\begin{array}{c}\text { 38/3121 }(1.2 \%) \\
\text { Immediate } \\
\text { 33/3121 }(1.1 \%) \\
\text { Delayed }\end{array}$ & $(24)$ \\
\hline Total & & 15004 & 655 & 6620 & 49 & 139 & \\
\hline
\end{tabular}

${ }^{\mathrm{a} R C T}$, randomized controlled trials; ${ }^{\mathrm{R} C C}$, retrospective case-control; Immediate, immediate bleeding, Delayed, delayed bleeding; N/A, not available; ASA, aspirin; NSAIDS, non-steroidal anti-inflammatory drugs.

Table II. Quality assessment of randomized controlled trials using the Jadad Scale.

\begin{tabular}{lcccccc}
\hline Author, year & Randomization & $\begin{array}{c}\text { Allocation } \\
\text { concealment }\end{array}$ & $\begin{array}{c}\text { Double } \\
\text { blind }\end{array}$ & $\begin{array}{c}\text { Random sequence } \\
\text { generation }\end{array}$ & $\begin{array}{c}\text { Jadad } \\
\text { Dropouts }\end{array}$ & $\begin{array}{c}\text { score } \\
\text { (Refs.) }\end{array}$ \\
\hline $\begin{array}{l}\text { Feagins } \text { et al, } 2013 \\
\text { Chan } \text { et al, } 2019\end{array}$ & Yes & Yes & Unclear & Yes & Y/10 & 3 \\
\hline
\end{tabular}

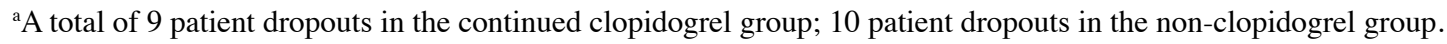

Table III. Quality assessment of randomized controlled trials by the Newcastle-Ottawa scale.

\begin{tabular}{|c|c|c|c|c|c|}
\hline Author, year & Selection & Comparability & Exposure or outcome & Total score & (Refs.) \\
\hline Feagins et al, 2011 & +++ & ++ & + & 6 & (8) \\
\hline Singh et al, 2010 & +++ & ++ & + & 6 & (6) \\
\hline Grossman et al, 2010 & +++ & ++ & + & 6 & (24) \\
\hline
\end{tabular}

and 84/4,771 patients not receiving clopidogrel developed immediate PPB. The immediate PPB rate was slightly higher in the continued clopidogrel group $(5.77 \%)$ compared with the control group (1.77\%); however, this 


\begin{tabular}{|c|c|c|c|c|c|c|c|c|c|c|c|}
\hline Study or subgroup & $\begin{array}{l}\text { Clopido } \\
\text { Events }\end{array}$ & $\begin{array}{l}\text { grel } \\
\text { Total }\end{array}$ & $\begin{array}{l}\text { Contro } \\
\text { Events }\end{array}$ & $\begin{array}{l}\text { ol } \\
\text { Total }\end{array}$ & Weight & $\begin{array}{l}\text { Risk ratio } \\
\mathrm{M}-\mathrm{H}, \text { Fixed, } 95 \% \mathrm{Cl}\end{array}$ & & $\begin{array}{r}\text { Risk } \\
\text { M-H, Fixe }\end{array}$ & ratio & & \\
\hline Chan et al. 2018 & 13 & 106 & 10 & 110 & $29.5 \%$ & $1.35[0.62,2.94]$ & & & & & \\
\hline Feagins and lqbal et al. 2013 & 21 & 219 & 14 & 297 & $35.7 \%$ & $2.03[1.06,3.91]$ & & & & & \\
\hline Feagins et al. 2011 & 1 & 118 & 6 & 1849 & $2.2 \%$ & $2.61[0.32,21.52]$ & & & & & \\
\hline Grossman et al. 2010 & 6 & 70 & 71 & 3121 & $9.3 \%$ & $3.77[1.69,8.38]$ & & & & & \\
\hline Singh et al. 2010 & 8 & 142 & 38 & 1243 & $23.4 \%$ & $1.84[0.88,3.87]$ & & & & & \\
\hline Total $(95 \% \mathrm{Cl})$ & & 655 & & 6620 & $100.0 \%$ & $1.96[1.36,2.83]$ & & & & & \\
\hline Total events & 49 & & 139 & & & & & & & & \\
\hline \multicolumn{7}{|c|}{$\begin{array}{l}\text { Heterogeneity: } \mathrm{Chi}^{2}=3.56, \mathrm{df}=4(P=0.47) ;\left.\right|^{2}=0 \% \\
\text { Test for overall effect: } Z=3.60(P=0.0003)\end{array}$} & 0.01 & $\begin{array}{c}0.1 \\
\text { Clopidogrel }\end{array}$ & Control & 10 & 100 \\
\hline
\end{tabular}

Figure 2. Colonoscopic post-polypectomy bleeding in continued clopidogrel users compared with non-clopidogrel users. Control, non-clopidogrel users; events, immediate and delayed bleeding. CI, confidence interval.

\begin{tabular}{|c|c|c|c|c|c|c|c|c|c|c|c|}
\hline Study or subgroup & $\begin{array}{l}\text { Clopido } \\
\text { Events }\end{array}$ & $\begin{array}{l}\text { grel } \\
\text { Total }\end{array}$ & $\begin{array}{l}\text { Contro } \\
\text { Events }\end{array}$ & $\begin{array}{l}\text { ol } \\
\text { Total }\end{array}$ & Weight & $\begin{array}{l}\text { Risk ratio } \\
\mathrm{M}-\mathrm{H} \text {. Fixed, } 95 \% \mathrm{Cl}\end{array}$ & & $\begin{array}{r}\text { Risk } \\
\text { M-H. Fixe }\end{array}$ & $\begin{array}{l}\text { ratio } \\
\text { d. } 95 \% \mathrm{Cl}\end{array}$ & & \\
\hline Chan et al. 2018 & 9 & 106 & 6 & 110 & $23.8 \%$ & $1.56[0.57,4.22]$ & & & & & \\
\hline Feagins and lqbal et al. 2013 & 16 & 219 & 14 & 297 & $48.0 \%$ & $1.55[0.77,3.11]$ & & & - & & \\
\hline Grossman et al. 2010 & 3 & 70 & 38 & 3121 & $6.7 \%$ & $3.52[1.11,11.13]$ & & & & & \\
\hline Singh et al. 2010 & 3 & 142 & 26 & 1243 & $21.5 \%$ & $1.01[0.31,3.29]$ & & & & & \\
\hline Total $(95 \% \mathrm{Cl})$ & & 537 & & 4771 & $100.0 \%$ & $1.57[0.98,2.51]$ & & & & & \\
\hline Total events & 31 & & 84 & & & & & & & & \\
\hline $\begin{array}{l}\text { Heterogeneity: } \mathrm{Chi}^{2}=2.43, \mathrm{df} \\
\text { Test for overall effect: } Z=1.87\end{array}$ & $\begin{array}{l}3(P=0.4 \\
P=0.06)\end{array}$ & $9) ; 1^{2}=0$ & & & & & 0.01 & $\begin{array}{ll}0.1 & 1 \\
\text { Clopidogrel }\end{array}$ & Control & 10 & 100 \\
\hline
\end{tabular}

Figure 3. Immediate bleeding in continued clopidogrel users compared with non-clopidogrel users. Events, immediate bleeding. CI, confidence interval.

\begin{tabular}{|c|c|c|c|c|c|c|c|c|c|c|c|}
\hline \multirow[b]{2}{*}{ Study or subgroup } & \multicolumn{2}{|c|}{ Clopidogrel } & \multicolumn{2}{|c|}{ Control } & \multirow{2}{*}{ Weight } & \multirow{2}{*}{$\begin{array}{l}\text { Odds ratio } \\
\text { M-H. Fixed. } 95 \% \mathrm{Cl}\end{array}$} & \multicolumn{5}{|c|}{ Odds ratio } \\
\hline & Events & Total & Events & Total & & & & M-H, Fix & ed. $95 \% \mathrm{Cl}$ & & \\
\hline Chan et al. 2018 & 4 & 106 & 4 & 110 & $43.6 \%$ & $1.04[0.25,4.27]$ & & & & & \\
\hline Feagins and lgbal et al. 2013 & 5 & 210 & 0 & 286 & $4.8 \%$ & $15.34[0.84,278.88]$ & & & & & \\
\hline Feagins et al. 2011 & 1 & 118 & 6 & 1849 & $8.2 \%$ & $2.63[0.31,21.99]$ & & & & & \\
\hline Grossman et al. 2010 & 3 & 70 & 33 & 3121 & $16.0 \%$ & $4.19[1.25,14.00]$ & & & & & \\
\hline Singh et al. 2010 & 5 & 142 & 12 & 1243 & $27.4 \%$ & $3.74[1.30,10.79]$ & & & & & \\
\hline Total $(95 \% \mathrm{Cl})$ & & 646 & & 6609 & $100.0 \%$ & $3.10[1.60,5.98]$ & & & & & \\
\hline Total events & 18 & & 55 & & & & & & & & \\
\hline $\begin{array}{l}\text { Heterogeneity: } \mathrm{Chi}^{2}=3.85, \mathrm{df} \\
\text { Test for overall effect: } Z=3.36\end{array}$ & $\begin{array}{l}4(P=0.4 \\
P=0.0008\end{array}$ & $; I^{2}=0$ & & & & & 0.01 & 0.1 & 1 & 10 & 100 \\
\hline
\end{tabular}

Figure 4. Delayed bleeding in continued clopidogrel users compared with non-clopidogrel users. Events, delayed bleeding. CI, confidence interval.

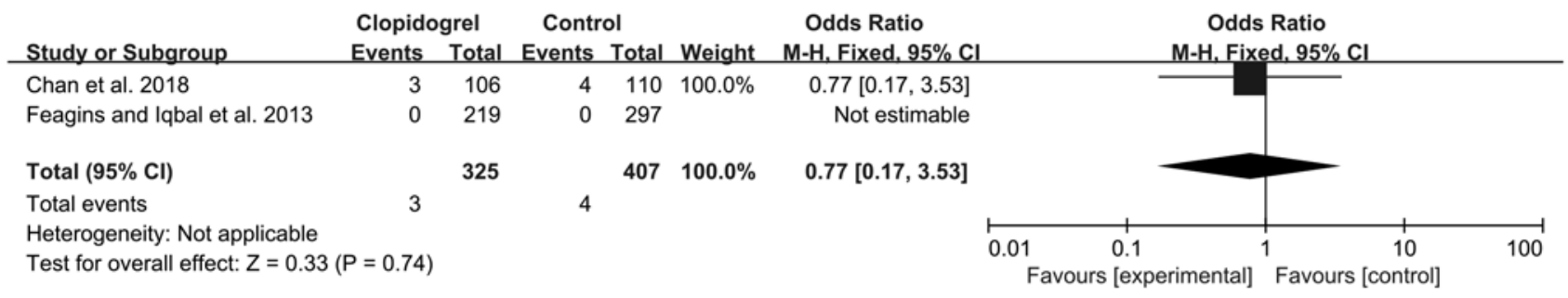

Figure 5. Serious cardiovascular events in uninterrupted clopidogrel users compared with non-clopidogrel users. Events, serious cardiovascular events. CI, confidence interval.

was not significant (fixed-effect model; $\mathrm{P}=0.06$; RR, 1.57 ; $95 \%$ CI $0.98-2.51)$ and there was no heterogeneity $(\mathrm{P}=0.49$; $\mathrm{I}^{2}, 0 \%$; Fig. 3).

Delayed PPB. A total of five studies reported delayed PPB. As shown in Fig. 4, the pooled RR of the delayed PPB was increased to $3.10(\mathrm{P}=0.0008 ; 95 \% \mathrm{CI}, 1.60-5.98)$, based on a fixed-effects model with no heterogeneity $\left(\mathrm{P}=0.43 ; \mathrm{I}^{2}\right.$, $0 \%$ ).

Serious cardio-thrombotic events. Only two studies assessed serious cardio-thrombotic events, which were observed in 3 out of 325 patients on clopidogrel $(0.92 \%)$ compared with 4 out of 407 patients $(0.98 \%)$ in the control group, with a 

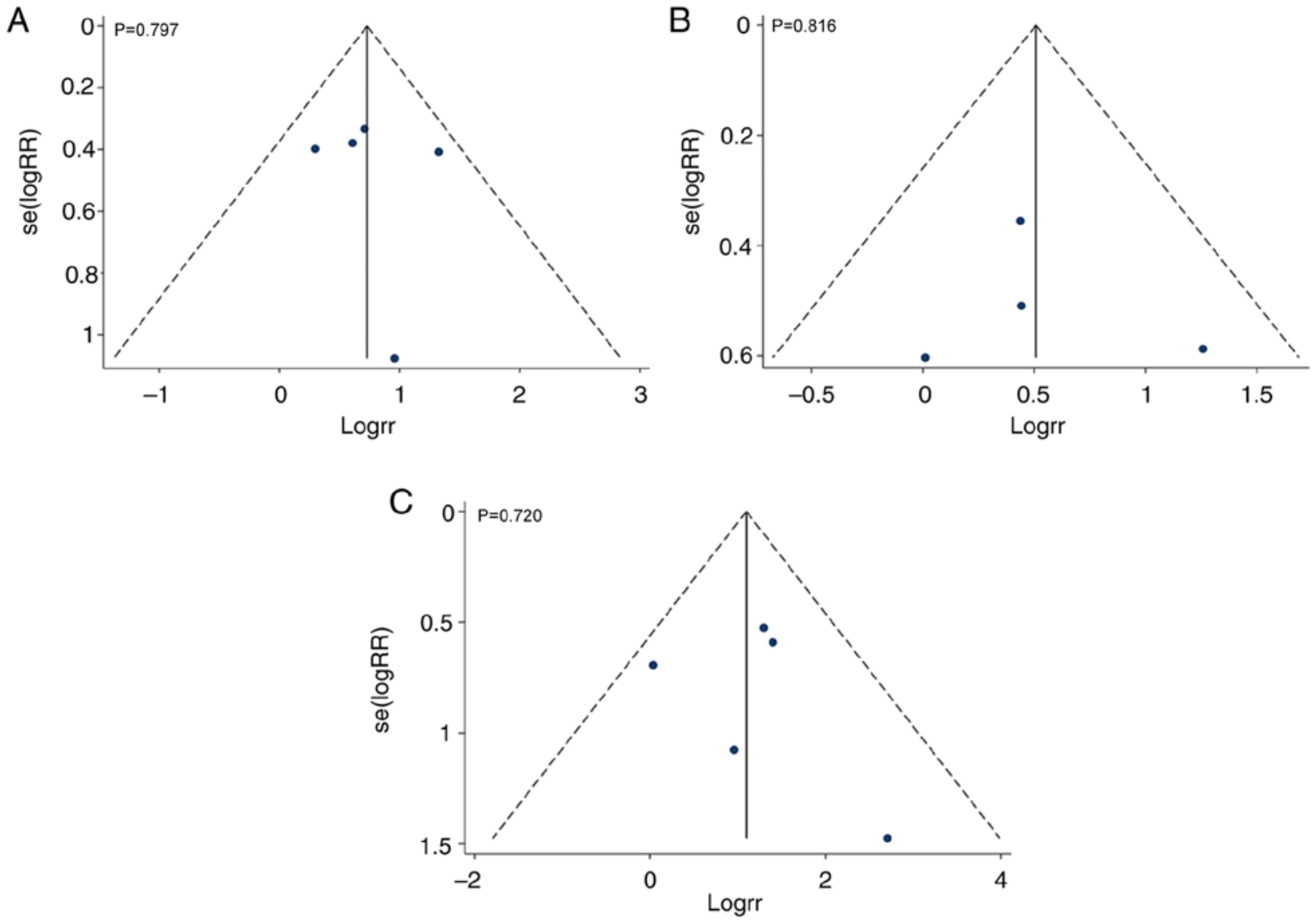

Figure 6. Funnel plot to assess publication bias. (A) Colonoscopic PPB publication bias. (B) Immediate PPB publication bias. (C) Delayed PPB publication bias. $\mathrm{PPB}$, post-polypectomy bleeding; RR, risk ratio; se, standard error.

non-significant pooled $\mathrm{RR}$ of 0.78 within 30 days $(\mathrm{P}=0.74$; 95\%CI, 0.18-3.40; Fig. 5).

Publication bias. There was no publication bias in colonoscopic PPB, immediate PPB and delayed PPB demonstrated by funnel plot analysis $(\mathrm{P}=0.797, \mathrm{P}=0.816$ and $\mathrm{P}=0.720$, respectively; Fig. 6).

\section{Discussion}

Colorectal cancer (CRC) ranks third in terms of incidence but second in terms of mortality of all cancer types in the USA (25). It is estimated that there will be 140,250 new cases and 50,630 deaths in the United States in 2018 (25). Currently, the preferred modality for detection and prevention of CRC is an endoscopic procedure every 10 years, beginning at 50 years of age. However, most patients with known heart disease are over 50 years and are taking clopidogrel and other thienopyridines (26). Active antiplatelet therapy complicates colorectal detection by increasing the risk of complications, including PPB. Interruption of antiplatelet therapy may pose a high thrombosis risk and be associated with high mortality inpatients during endoscopic procedures, particularly polypectomy (27). In the present study, a meta-analysis was performed to estimate the rate of PPB in patients on continued clopidogrel.

The results of the present study demonstrated that continued clopidogrel increased the occurrence of delayed
PPB, which is consistent with the current guidelines and previously published meta-analyses $(10,11)$. However, one published meta-analysis included only one prospective controlled trial and four retrospective case-control studies, and the definition of delayed PPB was inconsistent between these studies; four studies defined delayed PPB as bleeding within 4 weeks, whereas another study defined it as bleeding within 15 days, indeed, this inconsistency may affect the accuracy of the results and publication bias was not assessed (10). Another published meta-analysis included only two retrospective case-control studies; however, one study defined delayed PPB as bleeding within 15 days after polypectomy (11). In the present meta-analysis, two prospective controlled trials and three retrospective case-control studies were included, delayed PPB was defined as bleeding within 4 weeks or 30 days after post-polypectomy, and all patients who were receiving concomitant aspirin or other NSAIDs were included. Therefore, the present study evaluated the rate of PPB more rigorously. To the best of our knowledge, the present study is the first to demonstrate that continued clopidogrel therapy did not increase the number of serious cardio-thrombotic events.

A number of limitations remain in this meta-analysis. The first major limitation was the small number of RCTs, which may limit the statistical power of these findings. The present study demonstrated that continued clopidogrel therapy did not increase the number of serious cardio-thrombotic events, which was inconsistent with previous publications $(14,15)$, 
and thus required further confirmation. Secondly, the present study included three retrospective case-control studies, which can lead to selection bias. Thirdly, patient-associated factors contributing to PPB have been described, such as increased age (28), chronic renal disease (28), coronary artery disease (CAD) (29) and hypertension (30). In the present study, the patients on clopidogrel were older and had more comorbidities than the non-clopidogrel users, and this difference contributed to elevated rates of PPB in the continued clopidogrel group. Furthermore, polyp- and procedure-associated risk factors, such as polyp size $(31,32)$, polyp location $(31,32)$, the number of removed polyps (33), endoscopists experience $(32,34)$ and removal modality (28), were associated with the rate of PPB. However, these factors were not considered in the present study, due to limited data. Moreover, because endoscopists were not blinded during polypectomy in the study, prophylactic clip placement was routinely applied after polypectomy, which could decrease the PPB rate in the clopidogrel group $(18,28)$. Parikh et al (35) suggested that the prophylactic clip placement may be cost-effective for patients on clopidogrel therapy following polypectomy. However, 2 randomized controlled trials and 1 meta-analysis showed that preventative clip placement did not significantly benefit patients receiving thienopyridines (36-38). The present study does not discriminate the effect of concomitant aspirin or NSAID therapy. A meta-analysis showed that the rate of delayed PPB was elevated in patients on clopidogrel therapy, who were also receiving other anti-platelet medicines, compared with non-clopidogrel users (11). However, a retrospective case control study did not yield similar results (39). Finally, whether resuming antiplatelet agents may increase the rate of delayed PPB after polypectomy remains in question. A retrospective case control study showed that resuming the intake of antithrombotics earlier (within 1 week) can elevate the rate of delayed PPB (39). At present, little data have been published on this subject.

Despite these limitations, the present study also offers some important implications for clinical practice. The effect of continued clopidogrel therapy on serious cardio-thrombotic events, compared with discontinued clopidogrel, requires further study. However, the present study showed that the rates of immediate PPB and delayed PPB in patients on continued clopidogrel were 5.77 and $2.78 \%$, respectively. Moreover, although the rate of PPB was significantly higher in the continued clopidogrel group, it was controlled adequately by blood transfusions and repeat colonoscopy, and no patients died or required surgery. However, these treatments could also increase the economic burden of medical health care. The findings of the present study suggested that endoscopists should prepare to prevent bleeding in the perioperative period, in the event that polypectomy cannot be reasonably postponed and clopidogrel therapy could not be interrupted.

\section{Acknowledgements}

The authors would like to thank Professor Yu-Qiang Nie (Guangzhou First People's Hospital, Guangzhou Medical University) for their support with the methods and Professor Wei Fan (Cedars-Sinai Medical Center) for revising the manuscript.

\section{Funding}

This study was supported by Natural Science Foundation of Hunan Province (grant no. 2017JJ3270), Natural Science Foundation of Guangdong Province (grant no. 2018A0303100024), Three Engineering Training Funds in Shenzhen (grant nos. SYLY201718, SYJY201714 and SYLY201801) and Technical Research and Development Project of Shenzhen (grant no. JCYJ20150403101028164).

\section{Availability of data and materials}

All data generated or analyzed during the present study are included in this published article.

\section{Authors' contributions}

$\mathrm{DL}, \mathrm{XC}, \mathrm{LW}$ and JY designed the study and reviewed the manuscript. DL and XC drafted the manuscript and performed statistical analysis. JW, ZY, CW, FX, XF and ZX, screened for literature and assessed the quality of studies. DZ, TL and ML retrieved the data. All authors have read and approved the final manuscript.

\section{Ethics approval and consent to participate}

Not applicable.

\section{Patient consent for publication}

Not applicable.

\section{Competing interests}

The authors declare that they have no competing interests.

\section{References}

1. Kim AS and Johnston SC: Global variation in the relative burden of stroke and ischemic heart disease. Circulation 124: 314-323, 2011.

2. Writing Group Members; Mozaffarian D, Benjamin EJ, Go AS Arnett DK, Blaha MJ, Cushman M, Das SR, de Ferranti S, Després JP, et al: Executive summary: Heart disease and stroke statistics-2016 update: A report from the American heart association. Circulation 133: 447-454, 2016.

3. Rosen L, Bub DS, Reed JF III and Nastasee SA: Hemorrhage following colonoscopic polypectomy. Dis Colon Rectum 36: 1126-1131, 1993.

4. Reaume KT, Regal RE and Dorsch MP: Indications for dual antiplatelet therapy with aspirin and clopidogrel: Evidence-based recommendations for use. Ann Pharmacother 42: 550-557, 2008.

5. Spertus JA, Kettelkamp R, Vance C, Decker C, Jones PG, Rumsfeld JS, Messenger JC, Khanal S, Peterson ED, Bach RG, et al: Prevalence, predictors, and outcomes of premature discontinuation of thienopyridine therapy after drug-eluting stent placement: Results from the PREMIER registry. Circulation 113: 2803-2809, 2006.

6. Singh M, Mehta N, Murthy UK, Kaul V, Arif A and Newman N: Postpolypectomy bleeding in patients undergoing colonoscopy on uninterrupted clopidogrel therapy. Gastrointest Endosc 71: 998-1005, 2010.

7. Carter D, Beer-Gabel M, Eliakim R, Novis B, Avidan B and Bardan E: Management of antithrombotic agents for colonoscopic polypectomies in Israeli gastroenterologists relative to published guidelines. Clin Res Hepatol Gastroenterol 37: 514-518, 2013.

8. Feagins LA, Uddin FS, Davila RE, Harford WV and Spechler SJ: The rate of post-polypectomy bleeding for patients on uninterrupted clopidogrel therapy during elective colonoscopy is acceptably low. Dig Dis Sci 56: 2631-2638, 2011. 
9. Feagins LA, Iqbal R, Harford WV, Halai A, Cryer BL, Dunbar KB, Davila RE and Spechler SJ: Low rate of postpolypectomy bleeding among patients who continue thienopyridine therapy during colonoscopy. Clin Gastroenterol Hepatol 11: 1325-1332, 2013.

10. Gandhi S, Narula N, Mosleh W, Marshall JK and Farkouh M: Meta-analysis: Colonoscopic post-polypectomy bleeding in patients on continued clopidogrel therapy. Aliment Pharmacol Ther 37: 947-952, 2013.

11. Shalman D and Gerson LB: Systematic review with meta-analysis: The risk of gastrointestinal haemorrhage post-polypectomy in patients receiving anti-platelet, anti-coagulant and/or thienopyridine medications. Aliment Pharmacol Ther 42: 949-956, 2015.

12. Kato M, Uedo N, Hokimoto S, Ieko M, Higuchi K, Murakami K and Fujimoto K: Guidelines for gastroenterological endoscopy in patients undergoing antithrombotic treatment: 2017 appendix on anticoagulants including direct oral anticoagulants. Dig Endosc 30: 433-440, 2018.

13. Chan FKL, Goh KL, Reddy N, Fujimoto K, Ho KY, Hokimoto S Jeong YH, Kitazono T, Lee HS, Mahachai V, et al: Management of patients on antithrombotic agents undergoing emergency and elective endoscopy: Joint Asian Pacific Association of Gastroenterology (APAGE) and Asian Pacific Society for Digestive Endoscopy (APSDE) practice guidelines. Gut 67: 405-417, 2018.

14. Mehran R, Baber U, Steg PG, Ariti C, Weisz G, Witzenbichler B, Henry TD, Kini AS, Stuckey T, Cohen DJ, et al: Cessation of dual antiplatelet treatment and cardiac events after percutaneous coronary intervention (PARIS): 2 year results from a prospective observational study. Lancet 382: 1714-1722, 2013.

15. Eisenberg MJ, Richard PR, Libersan D and Filion KB: Safety of short-term discontinuation of antiplatelet therapy in patients with drug-eluting stents. Circulation 119: 1634-1642, 2009.

16. Chan FKL, Kyaw MH, Hsiang JC, Suen BY, Kee KM, Tse YK, Ching JYL, Cheong PK, Ng D, Lam K, et al: Risk of postpolypectomy bleeding with uninterrupted clopidogrel therapy in an industry-independent, double-blind, randomized trial. Gastroenterology 156: 918-925, 2019.

17. Plumé Gimeno G, Bustamante-Balén M, Satorres Paniagua C, Díaz Jaime FC and Cejalvo Andújar MJ: Endoscopic resection of colorectal polyps in patients on antiplatelet therapy: An evidence-based guidance for clinicians. Rev Esp Enferm Dig 109: 49-59, 2017.

18. Abdel Samie A, Theilmann L and Labenz J; ALGK: Endoscopic procedures in patients under clopidogrel or dual antiplatelet therapy: A survey among German gastroenterologists and current guidelines. Z Gastroenterol 52: 425-428, 2014.

19. Liberati A, Altman DG, Tetzlaff J, Mulrow C, Gøtzsche PC, Ioannidis JP, Clarke M, Devereaux PJ, Kleijnen J and Moher D: The PRISMA statement for reporting systematic reviews and meta-analyses of studies that evaluate health care interventions: Explanation and elaboration. Ann Intern Med 151: W65-W94, 2009

20. Nelson DB, McQuaid KR, Bond JH, Lieberman DA, Weiss DG and Johnston TK: Procedural success and complications of large-scale screening colonoscopy. Gastrointest Endosc 55: 307-314, 2002

21. Stroup DF, Berlin JA, Morton SC, Olkin I, Williamson GD, Rennie D, Moher D, Becker BJ, Sipe TA and Thacker SB: Meta-analysis of observational studies in epidemiology: A proposal for reporting. Meta-analysis Of Observational Studies in Epidemiology (MOOSE) group. JAMA 283: 2008-2012, 2000

22. Jadad AR, Moore RA, Carroll D, Jenkinson C, Reynolds DJ, Gavaghan DJ and McQuay HJ: Assessing the quality of reports of randomized clinical trials: Is blinding necessary? Control Clin Trials 17: 1-12, 1996.

23. Higgins JP, Thompson SG, Deeks JJ and Altman DG: Measuring inconsistency in meta-analyses. BMJ 327: 557-560, 2003.

24. Grossman EB, Maranino AN, Zamora DC, et al: Antiplatelet Medications Increase the Risk of Post-Polypectomy Bleeding. GastrointestEndosc 71: AB138, 2010.
25. Siegel RL, Miller KD and Jemal A: Cancer statistics, 2018. CA Cancer J Clin 68: 7-30, 2018.

26. Zhao D, Liu J, Wang M, Zhang X and Zhou M: Epidemiology of cardiovascular disease in China: Current features and implications. Nat Rev Cardiol 16: 203-212, 2019.

27. Iakovou I, Schmidt T, Bonizzoni E, Ge L, Sangiorgi GM, Stankovic G, Airoldi F, Chieffo A, Montorfano M, Carlino M, et al: Incidence, predictors, and outcome of thrombosis after successful implantation of drug-eluting stents. JAMA 293: 2126-2130, 2005 .

28. Kim HS, Kim TI, Kim WH, Kim YH, Kim HJ, Yang SK, Myung SJ, Byeon JS, Lee MS, Chung IK, et al: Risk factors for immediate postpolypectomy bleeding of the colon: A multicenter study. Am J Gastroenterol 101: 1333-1341, 2006

29. Sawhney MS, Salfiti N, Nelson DB, Lederle FA and Bond JH: Risk factors for severe delayed postpolypectomy bleeding. Endoscopy 40: 115-119, 2008.

30. Watabe H, Yamaji Y, Okamoto M, Kondo S, Ohta M, Ikenoue T, Kato J, Togo G, Matsumura M, Yoshida H, et al: Risk assessment for delayed hemorrhagic complication of colonic polypectomy: Polyp-related factors and patient-related factors. Gastrointest Endosc 64: 73-78, 2006.

31. Rutter MD, Nickerson C, Rees CJ, Patnick J and Blanks RG: Risk factors for adverse events related to polypectomy in the English Bowel Cancer Screening Programme. Endoscopy 46: 90-97, 2014.

32. Choung BS, Kim SH, Ahn DS, Kwon DH, Koh KH, Sohn JY, Park WS, Kim IH, Lee SO, Lee ST and Kim SW: Incidence and risk factors of delayed postpolypectomy bleeding: A retrospective cohort study. J Clin Gastroenterol 48: 784-789, 2014.

33. Heldwein W, Dollhopf M, Rösch T, Meining A, Schmidtsdorff G, Hasford J, Hermanek P, Burlefinger R, Birkner B, Schmitt W, et al: The Munich Polypectomy Study (MUPS): Prospective analysis of complications and risk factors in 4000 colonic snare polypectomies. Endoscopy 37: 1116-1122, 2005.

34. Rabeneck L, Paszat LF, Hilsden RJ, Saskin R, Leddin D, Grunfeld E, Wai E, Goldwasser M, Sutradhar R and Stukel TA: Bleeding and perforation after outpatient colonoscopy and their risk factors in usual clinical practice. Gastroenterology 135: 1899-1906.e1891, 2008

35. Parikh ND, Zanocco K, Keswani RN and Gawron AJ: A cost-efficacy decision analysis of prophylactic clip placement after endoscopic removal of large polyps. Clin Gastroenterol Hepatol 11: 1319-1324, 2013.

36. Matsumoto M, Kato M, Oba K, Abiko S, Tsuda M, Miyamoto S, Mizushima T, Ono M, Omori S, Takahashi M, et al: Multicenter randomized controlled study to assess the effect of prophylactic clipping on post-polypectomy delayed bleeding. Dig Endosc 28: 570-576, 2016

37. Boumitri C, Mir FA, Ashraf I, Matteson-Kome ML, Nguyen DL, Puli SR and Bechtold ML: Prophylactic clipping and post-polypectomy bleeding: A meta-analysis and systematic review. Ann Gastroenterol 29: 502-508, 2016.

38. Dokoshi T, Fujiya M, Tanaka K, Sakatani A, Inaba Y, Ueno N, Kashima S, Goto T, Sasajima J, Tominaga M, et al: A randomized study on the effectiveness of prophylactic clipping during endoscopic resection of colon polyps for the prevention of delayed bleeding. Biomed Res Int 2015: 490272, 2015.

39. Lin D, Soetikno RM, McQuaid K, Pham C, Doan G, Mou S, Shergill AK, Somsouk M, Rouse RV and Kaltenbach T: Risk factors for postpolypectomy bleeding in patients receiving anticoagulation or antiplatelet medications. Gastrointest Endosc 87: 1106-1113, 2018.

(i) $($ This work is licensed under a Creative Commons Attribution-NonCommercial-NoDerivatives 4.0 International (CC BY-NC-ND 4.0) License. 